\title{
İntrarenal reflü
}

\author{
Intrarenal reflux
}

Neslihan Yılmaz, Selçuk Yüksel

\begin{abstract}
Özet
Vezikoüreteral reflü (VUR), idrarın mesaneden böbreklere üreter yoluyla geri aktığı durum olarak adlandırılır. İntrarenal reflü (IRR), idrarın böbrek pelvisinden toplayıcı kanallar içine doğru geri kaçması (idrarın piyelotubuler geri akımı) olarak tanımlanır. IRR genellikle yüksek dereceli VUR ile birlikte bulunur. Bu olgu sunumunda yüksek dereceli VUR'u ve ona eşlik eden IRR'si olan bir erkek çocuk sunulmuştur. Hasta 2 yıllık izleminde antibiyotik profilaksisi kullanmamış, IRR'si kendiliğinden düzelirken VUR'u da gerilemiştir. VUR'lu hastalardaki IRR insidansı \%2 ile \%10 arasında bildirilmektedir. Yüksek dereceli VUR'un spontan düzeldiği bilindiğinden, IRR'nin eşlik ettiği yüksek dereceli VUR'ların düşük doz antibiyotik proflaksisi ile izlenmesi önerilmektedir. Çünkü IRR var olsa bile ateşli idrar yolu enfeksiyonu (IYYE) olmadığı sürece prognozun fazlaca etkilenmediği belirlenmiştir. Hastada antibiyotik profilaksisi kullanılamamış ve takip döneminde hasta 2 kez IYE geçirmiştir. Buna rağmen IRR kaybolmuş, VUR derecesi belirgin olarak gerilemiştir. IRR ile birlikte böbrekte hasar riski artar. Bu nedenle IRR varlığı yüksek dereceli VUR'lu bebekler ve yeni doğanlarda daha dikkatle değerlendirilmelidir.
\end{abstract}

Anahtar Kelimeler: Veziko-üreteral reflü, skar, renal papilla, profilaksi.

Yılmaz N, Yüksel S. İntrarenal reflü. Pam Tıp Derg 2019;12:347-350.

\begin{abstract}
Vesicoureteral reflux (VUR) is called a condition in which urine flows backward from the bladder to the kidneys via ureters. Intrarenal reflux (IRR) is defined as the urine back flow from the renal pelvis into the collecting ducts (pyelo-tubular backflow). IRR is usually associated with high-grade VUR. In this case report, a male infant with high-grade VUR associated with IRR was presented. During the 2-year follow-up, he did not use antibiotic prophylaxis, and his IRR improved spontaneously and VUR regressed. Incidence of IRR in patients with VUR is reported between $2 \%$ and $10 \%$. Since the high-grade VUR is known to spontaneously recover, it is recommended that high degree VUR associated IRR should be followed with low-dose antibiotic prophylaxis. Because, even if there is an IRR, many studies are reported that the prognosis cannot be affected, if there is no febrile urinary tract infection. The patient could not use antibiotic prophylaxis, and urinary tract infections occurred two times during the follow-up period. However, IRR was disappeared, and the degree of VUR decreased significantly. The risk of scarring in the kidney increases with the presence of IRR. Therefore, the presence of IRR should be evaluated more carefully in infants and neonates with high-grade VUR.
\end{abstract}

Key Words: Vesico-ureteral reflux, scar, renal papilla, prophylaxis.

Yılmaz N, Yüksel S. Intrarenal reflux. Pam Med J 2019;12:347-350.

\section{Giriş}

Vezikoüreteralreflü (VUR), idrarın mesane içinden üreterlere oradan da böbreğin pelvikalikseal sistemi içine doğru geri akımı olarak tanımlanır ve genellikle işeme esnasında ortaya çıkar. Uluslararası reflü çalışma grubunun 1985 yılında yaptığı sınıflamada VUR beş ayrı derece ile ifade edilmiştir [1]. İntrarenal reflü (IRR) ise, idrarın böbrek pelvisinden toplayıcı kanallar içine doğru geri kaçması (idrarın piyelotubuler geri akımı) olarak tanımlanır [2]. Bu durum işeme sistografisinde renal parankimin opaklaşması şeklinde ortaya çıkar. İlk kez 1965 yılında Brodeur ve ark. [3] tarafından tanımlanmıştır. Özellikle yenidoğanlarda ve bebeklerde yüksek dereceli VUR ile beraberdir [1]. Bununla birlikte her yüksek dereceli reflüde (III-V. derece) IRR olmayabilir. Literatürde VUR'lu hastalardaki IRR insidansı \%2 ile \%10 arasında bildirilmektedir [4].

Bu olgu sunumunda IRR'si olan bir bebeğin uzun süreli izlemi ve böbrekleriyle ilgili sonuçları

Neslihan Yılmaz, Uzm. Dr. Pamukkale Üniversitesi Tıp Fakültesi, Çocuk Nefroloji Bilim Dalı, DENiZLi, e-posta: nefrolojineslihan@gmail.com (orcid. org/0000-0001-8518-538X) (Sorumlu yazar)

Selçuk Yüksel, Prof. Dr. Pamukkale Üniversitesi Tıp Fakültesi, Çocuk Nefroloji Bilim Dalı, DENiZLi, e-posta: selcukyuksel.nephrology@gmail.com (orcid.org/0000-0001-9415-1640) 
temel alınarak literatür bilgisi ışığında takip ve tedavideki öneriler gözden geçirilmiştir.

\section{Olgu sunumu}

Üç aylık erkek hasta tekrarlayan idrar yolu enfeksiyonu olması nedeni ile kliniğimize kabul edildi. Hastanın öz geçmişinden yaşamının 6. ve 40. günlerinde iki kez ateşli idrar yolu enfeksiyonu geçirdiği, bu dönemde yapılan üriner sistem ultrasonografisinde bilateral hidronefrozunun olduğu öğrenildi. Geçirdiği üst üriner enfeksiyonları sonrası mahallinde yapılan Tc-99m dimerkaptosüksinik asitli (DMSA) böbrek sintigrafisinde sağ böbreğinin normalden küçük, sol böbreğin ise boyut ve parankim fonksiyonunun normal olduğu belirtilmiş. Prenatal dönemde ultrasonografik inceleme yapıldığı ancak herhangi bir anormal bulgudan bahsedilmemiş olduğu, 22 yaşındaki annenin ilk gebeliğinden son adet tarihine göre 41 haftalık normal doğum ile $2470 \mathrm{gr}$ canlı erkek bebek olarak doğduğu öğrenildi. İlave olarak, hastanın annesi tarafından fışkırtarak idrar yapabildiğinin gözlemlendiği ifade edildi. Aile öyküsünde bir özellik yoktu. Hastanın fizik muayenesinde vücut ağırlığı: 9,6 kg (3-10 p), boy: 81 cm (3-10 persantil), kan basıncı: $80 / 50 \mathrm{mmHg}$ ile birlikte diğer sistem ve genital muayeneleri normal olarak saptandı. Laboratuvar tetkiklerinde tam idrar incelemesi normal sınırlardaydı ve idrar kültüründe üreme saptanmadı. Diğer laboravar incelemelerinde, hemoglobin: 10,4 g/dl, lökosit: $8510 \mathrm{~K} / \mathrm{uL}$, trombosit: $508000 \mathrm{~K} /$ uL, üre: $16 \mathrm{mg} / \mathrm{dl}$, kreatinin: $0,2 \mathrm{mg} / \mathrm{dl}$ olarak bulundu. Kliniğimizdeki ilk renal ultrasonografi incelemesinde hastanın sağ böbrek uzun aksı $37 \mathrm{~mm}$, parankim kalınlığı $6 \mathrm{~mm}$, sol böbrek uzun aksı $45 \mathrm{~mm}$, parankim kalınlığı $8 \mathrm{~mm}$, iki taraflı böbrek parankim ekojenitelerinin de olağan olduğu görüldü. Aynı incelemede bilateral böbrek toplayıcı sisteminde dilatasyon ya da taş saptanmadı. Mesane boş olarak izlendi ve mesane duvar kalınlığı $3,5 \mathrm{~mm}$ olduğu belirlendi. Hastaya işeme sistografisi yapıldı ve dolduruluş ile işeme esnasında sağda 5 . derece solda 1. derece VUR olduğu görüldü (Resim 1). $\mathrm{Bu}$ incelemede ilave olarak sağ böbrekte IRR saptandı (Resim 1, ok ile işaretli). Hastanın ailesine bilgi verilerek tekrarlayan idrar yolu enfeksiyonlarının böbrek üzerinde yapabileceği olası ilave hasarlanmalar açısından antibiyotik profilaksisi başlanmak istendi. Ancak ailesi antibiyotik kullanmak istemediğini belirtince idrar yolu enfeksiyonu geçirip geçirmediğinin yakın takibi yapılması gerektiği belirtildi. Hasta 2 yıl boyunca profilaksisiz izlendi ve iki kez idrar yolu (ilki üst üriner, ikincisi alt üriner sistem) enfeksiyonu geçirdi. İzleminin ikinci yılı sonunda hastanın işeme sistografisi, üriner ultrasonografisi ve DMSA'lı böbrek sintigrafisi tekrarlandı. İşeme sistografisinde sağda 3 . derece VUR izlendi, ancak IRR düzelmişti (Resim 2). Solda ise toplayıcı sistemde VUR kaybolmuştu. $\mathrm{Bu}$ dönemde yapılan üriner sistem ultrasonografisinde; sağ böbrek $53 \times 24$ $\mathrm{mm}$, sol böbrek $65,5 \times 22 \mathrm{~mm}$ boyutlarında, parankim kalınlıkları her iki tarafta $9 \mathrm{~mm}$ olarak ölçüldü. DMSA'ı sintigrafi incelemesinde sağ böbrekte radyoaktif tutulumun \%35, sol böbrek \%65 oranında olduğu görüldü. Sağ böbrekteki tutulumun diffüz azalma şeklinde olduğu gözlendi (Resim 3). Hasta halen profilaksisiz ve idrar yolu enfeksiyonu açısından yakın takip ile izleme devam edilmektedir.

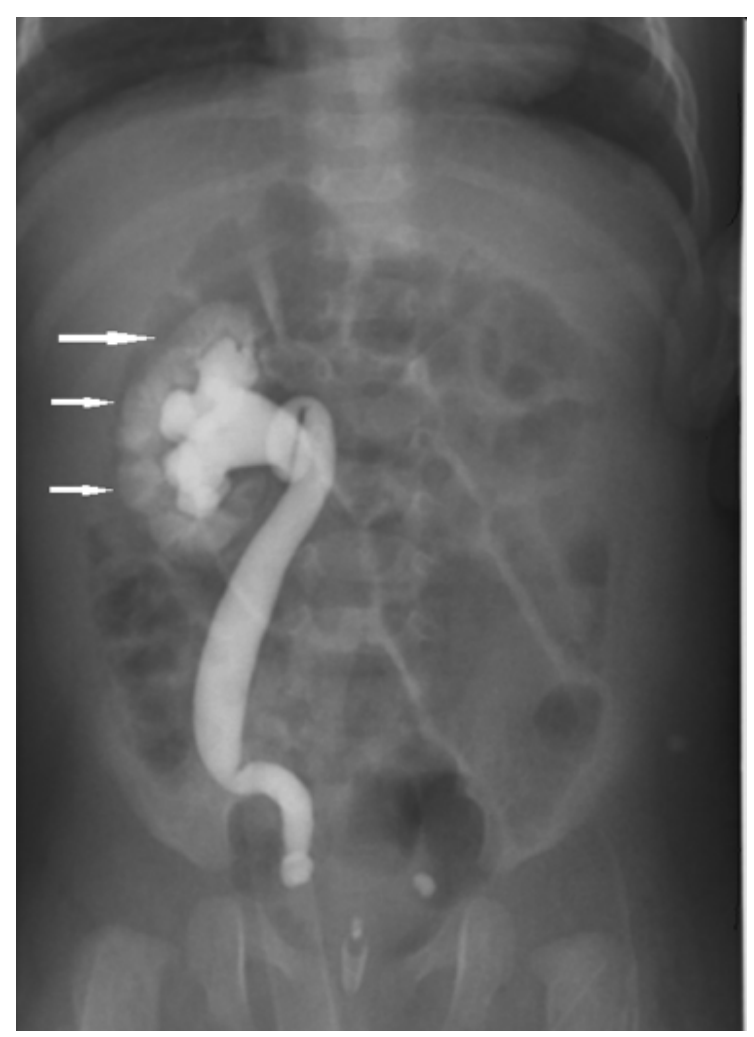

Resim 1. Sağ böbreğe IV. derece VUR ve aynı tarafa IRR (ok ile işaretli), sol böbreğe I. derece VUR (işeme sistografisi incelemesi). 


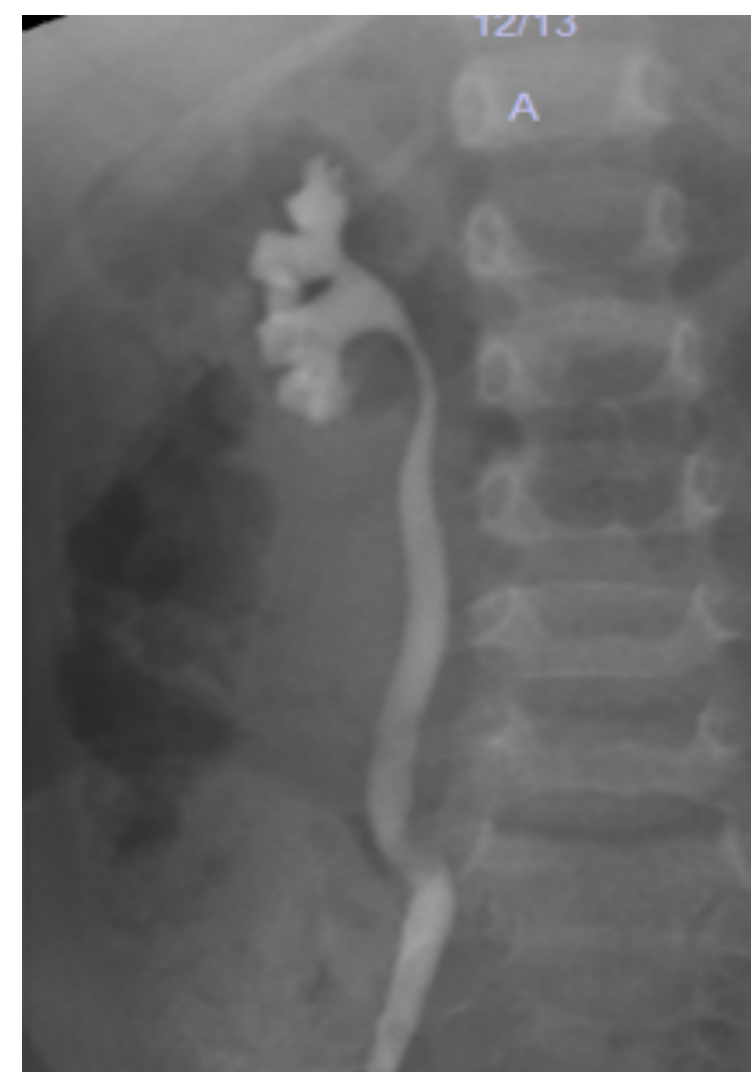

Resim 2. Sağ böbrekte IRR düzelmiş ve VUR derecesi azalmış, Sol böbreğe olan VUR düzelmiş (işeme sistografisi incelemesi).

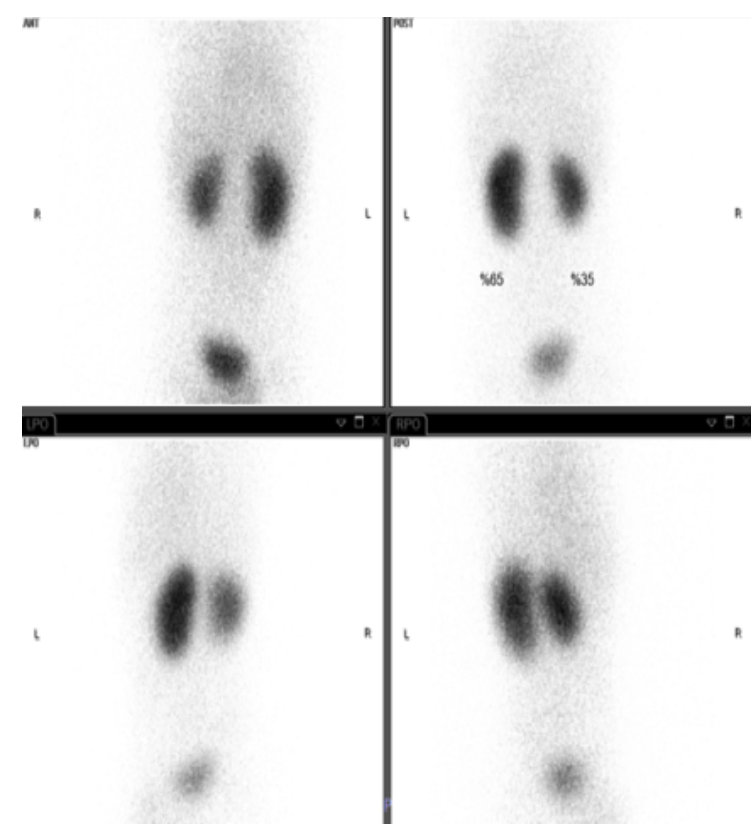

Resim 3. Sağ böbrekte radyoaktif tutulumun \%35 (diffüz azalma), sol böbrekte \%65 oranında olduğu görülen Tc99m DMSA'lı böbrek sintigraf.

\section{Tartışma}

Ransley ve Riston [5, 6], IRR'nin mekanizmasının konkav papillalarda bulunan toplayıcı kanal orifislerinin papilla yüzeyine dik açılmasından kaynaklandığını saptamışlardır. Burada temel sorun VUR ile kalikseal yapıya kadar gelen idrarın konkav papilla yüzeyine dik açılan toplayıcı kanal ağzından kolaylıkla içeri girebilmesive böylelikle IRR'yioluşturabilmesidir. Konveks papillalar ise orifisleri oblik seyrettiği için intra kalikseal basınç artınca bu duruma kapanarak yanıt vererek reflüye izin vermezler. Konkav papillalar böbreğin üst polünde daha fazla olmakla birlikte alt polde de bulunurlar $[5,6]$. Bu durum normalde patolojik değildir. Ancak VUR ile birilikte olursa renal hasara neden olabilir. Ateşli idrar yolu enfeksiyonu geçiren VUR'lu hastalarda IRR insidans। \%210 arasında değişmektedir $[4,7]$. IRR varlığı renal skar riskini artıır ve yaşamın ilerleyen dönemlerindehipertansiyon, proteinürive böbrek yetmezliğinin gelişmesine kadar gidebilen sonuçları beraberinde getirebilir. IRR tedavisi halen tartışmalıdır. Baubrova ve arkadaşları [8], IRR'si olan hastalar ile IRR'si olmayan yüksek dereceli reflü hastalarını tekrarlayan IYE sıklığı açısından karşılaştırmışlar ve arasında herhangi bir fark saptamamışlardır. Araştırmacılar medikal tedavi sonrası kendiliğinden düzelme oranlarının aynı olduğunu da 3 yıllık takiplerinde ispatlamışlardır. Çalışmanın sonunda hastaların spontan düzelme oranlarının aynı olması nedeniyle IRR varlığının daha agresif bir tedavi gerektirmediğini önermiştirler [8]. Fukui ve arkadaşları [9], IRR'si olmayan yüksek dereceli (3-5. derece) VUR'u olan hasta grubu ile IRR'nin eşlik ettiği yüksek dereceli VUR'u olan hasta gruplarının takibinde spontan düzelme açısından bir fark olmadığını göstermişlerdir. Ancak, belirli aralıklarla çekilen DMSA'ı böbrek sintigrafilerinde renal fonksiyon kaybının IRR'si olan grupta daha fazla olduğunu göstermişlerdir [9]. Shinaishi ve ark. [10], reflünün derecesinden çok araya giren ateşli enfeksiyonların renal hasar riskini artırdığını savunmaktadırlar. Geçmişte yapılan çalışmalarda ateşli idrar yolu enfeksiyonu ile birlikte IRR'nin varlığının renal skar riskini artırdığı bilindiğinden bu durumun bir cerrahi operasyon endikasyonu olduğu kabul edilirdi [11]. Günümüzde ise yüksek dereceli VUR'un spontan düzeldiği bilinmektedir. Bu nedenle IRR'nin eşlik ettiği yüksek dereceli vezikoüreteral reflülerin düşük doz paroflaksi 
ile izlenmesi önerilmektedir. Çünkü IRR var olsa bile ateşli idrar yolu enfeksiyonu olmadığı sürece prognozun fazlaca etkilenmediği belirlenmiştir. Bu konuda yapılan çalışmalar yukarıda da belirtildiği gibi IRR ile birlikte olan yüksek dereceli VUR'un ve IRR'nin eşlik etmediği yüksek derece VUR ile aynı oranda düzeldiğini göstermektedir. Olgumuzda profilaksi kullanılamamış, hasta 2 kez IYY geçirmiştir. Buna rağmen IRR kaybolmuş, VUR derecesi belirgin olarak gerilemiştir.

Sonuç olarak halen tedavisi tartışmalı olsa da, IRR daha yüksek oranda renal hasarla birlikte olması nedeniyle yüksek dereceli VUR'lu hastalarda dikkatle değerlendirilmelidir.

Çıkar İlişkisi: Yazarlar çıkar ilişkisi olmadığını beyan eder.

\section{Kaynaklar}

1- Lebowitz RL, Olbing $H$, Parkkulainen KV, Smellie JM, Tamminen-Möbius TE. International system of radiographic grading of vesicoureteric reflux. International Reflux Study in Children. Pediatr Radiol 1985;15:105-109.

2- Yüksel S. Intrarenal reflux. NDT Plus 2008;1:188-189. https://doi.org/10.1093/ndtplus/sfm050

3- Brodeur AE, Goyer RA, Melick W. A potential hazard of barium cystography. Radiology 1965;85:1080-1084. https://doi.org/10.1148/85.6.1080

4- Cremin BJ. Observations on vesico-ureteric reflux and intrarenal reflux: A review and survey of material. Clin Radiol 1979;30:607-621.

5- Ransley PG, Risdon RA. Renal papillary morphology in infants and young children. Urol Res 1975;3:111-113.

6- Ransley PG, Risdon RA. Renal papillary morphology and intrarenal reflux in the young pig. Urol Res 1975;3:105-109.

7- Gotoh T, Asano Y, Nonomura K, Togashi M, Koyanagi $\mathrm{T}$. Intrarenal reflux inchildren with vesicoureteral reflux. Nihon Hinyokika Gakkai Zasshi 1991;82:1480-1486.

8- Boubnova J, Sergent-Alaoui A, Deschênes G, Audry G. Evolution and prognosis value of intrarenal reflux. J Pediatr Urol 2011;7:638-643. https://doi.org/10.1016/j. jpurol.2010.09.015

9- Fukui S, Watanabe M, Yoshino K. Intrarenal reflux in primary vesicoureteral reflux. Int J Urol 2013;20:631636. https://doi.org/10.1111/iju.12015

10- Shiraishi K, Yoshino K, Watanabe M, Matsuyama H, Tanikaze S. Risk factors for breakthrough infection in children with primary vesicoureteral reflux. J Urol 2010;183:1527-1531.https://doi.org/10.1016/j. juro.2009.12.039
11- Uldall P, Frookjaer O, Kaas Ibsen K. Intrarenal reflux. Acta Paediatr Scand 1976;65:711-715. 